\title{
Angiotensin II Directly Triggers Endothelial Exocytosis via Protein Kinase C-Dependent Protein Kinase D2 Activation
}

\author{
Xiaona $\mathrm{Ge}^{1}$, Brad Low ${ }^{1}$, Mei Liang ${ }^{1}$, and Jian $\mathrm{Fu}^{1, *}$ \\ ${ }^{1}$ Center for Biomedical Research, University of Texas Health Center at Tyler, Tyler, Texas 75708, USA
}

Received May 16, 2007; Accepted August 21, 2007

\begin{abstract}
Angiotensin II (AII) has been reported to induce leukocyte adhesion to endothelium through up-regulation of P-selectin surface expression. However, the underlying molecular and cellular mechanisms remain unknown. P-selectin is stored in Weibel-Palade bodies (WPBs), large secretory granules, in endothelial cells. In this study, we examined the role of protein kinase D (PKD), a newly identified regulator of protein transport, in AII-induced WPB exocytosis and the resultant P-selectin surface expression. We demonstrated that PKD2 was rapidly activated by AII in endothelial cells through phosphorylation of the activation loop at Ser744/748. AII-induced PKD2 activation correlated with increased P-selectin surface expression. Furthermore, AII-regulated PKD2 activation is protein kinase $\mathrm{C}$ (PKC) $\alpha$-dependent. Importantly, knock-down of either PKD2 or PKC $\alpha$ expression inhibited AII-mediated P-selectin surface expression and monocyte adhesion. Our findings provide the first evidence that stimulation of P-selectin surface expression via PKC $\alpha$-dependent PKD2 activation could be an important mechanism in the early onset of AII-initiated endothelial adhesiveness.
\end{abstract}

Keywords: angiotensin, P-selectin, exocytosis, endothelial cell, protein kinase D (PKD)

\section{Introduction}

Angiotensin II (AII), a main effector of the reninangiotensin system (1), has been known to regulate blood pressure and control fluid/salt balance. However, in the last several years, there has been increasing evidence indicating that AII may also function as a potent pro-inflammatory mediator to induce vascular inflammation, which may lead to the pathogenesis of cardiovascular diseases such as atherosclerosis, myocardial infarction and stroke $(2-4)$.

Cell adhesion molecules are key players in vascular inflammation due to their important roles in mediating extravasation of leukocytes (5). The early tethering and rolling of leukocytes along the endothelium require $\mathrm{P}$ selectin surface expression (6). AII perfusion was reported to directly induce rapid and P-selectin-dependent leuokocyte rolling, adhesion, and transmigration across the endothelium $(7,8)$. However, the mechanism of AII-stimulated P-selectin surface expression in endo-

*Corresponding author. jian.fu@uthct.edu

Published online in J-STAGE

doi: 10.1254/jphs.FP0070858 thelial cells is still not elucidated. Leukocyte recruitment to the endothelium has been observed within minutes following infusion with AII (8). Since de novo protein synthesis and transport to the plasma membrane usually take hours, the early endothelial adhesiveness induced by AII is likely due to rapid release of P-selectin from pre-formed intracellular stores. Indeed, in endothelial cells, P-selectin is stored in secretory granules such as Weibel-Palade bodies (WPBs) (9). WPBs are endothelial specific secretory granules containing P-selectin and other pro-inflammatory mediators including von Willebrand factor (vWF), IL-8, eotaxin-3, and so on (9) Rapid WPB exocytosis induced by pro-inflammatory stimuli such as thrombin, histamine, and hypoxia plays pivotal roles in thrombosis and inflammation $(10,11)$. In the present study we examined the effects of AII on endothelial exocytosis and the resultant P-selectin surface expression.

AII has been reported to induce protein kinase $\mathrm{C}$ (PKC)-dependent protein kinase $\mathrm{D}$ (PKD) activation in several cell types $(12-14)$. PKD has recently emerged as an important regulator of membrane trafficking $(15-20)$. Studies from several groups have shown that PKD plays important roles in spatial and temporal 
regulation of protein transport and recycling at the plasma membrane $(15-20)$. However, the role of PKD in endothelial membrane trafficking and the regulation of PKD by pro-inflammatory signaling in endothelial cells remain undetermined. PKD is a newly identified serine/threonine protein kinase subfamily currently containing three members PKD1 (PKC $\mu$ ), PKD2, and PKD3 $(\mathrm{PKCv})(21)$. PKD activation is dependent on the phosphorylation of Ser744 and ser748 at the activation loop (21). Activation of PKD has been shown to regulate a variety of cellular responses, including secretion, migration, proliferation, and cell survival $(16,22-24)$. Signaling through G-protein-coupled receptor has been reported to mediate the phosphorylation of PKD at the activation loop $(25-27)$. Here, we specifically examined the role of PKD in AII-induced P-selectin surface expression in endothelial cells.

\section{Materials and Methods}

\section{Antibodies and reagents}

Mouse anti-P-selectin monoclonal antibody, rabbit anti-PKC $\alpha$ antibody, and goat anti-actin polyclonal antibody were obtained from Santa Cruz Biotechnology (Santa Cruz, CA, USA). P-selectin function-blocking monoclonal antibody was purchased from R\&D systems (Minneapolis, MN, USA). Rabbit anti-PKD2 antibody was from Calbiochem (San Diego, CA, USA). AII, AT1-receptor antagonist telmisartan, AT2-receptor antagonist PD123319, and rabbit antibody against vWF were obtained from Sigma (St. Louis, MO, USA). Rabbit anti-PKD (pSer744/748) was from cell signaling technology (Danvers, MA, USA). TMB substrate solutions and SuperSignal West Pico Chemiluminescent Substrate System were obtained from Pierce Biotechnology (Rockford, IL, USA). EGM-2 was from Cambrex (East Rutherford, NJ, USA). RPMI 1640 was from Invitrogen (Carlsbad, CA, USA).

\section{Cell culture}

HPAE (human pulmonary artery endothelial cells), HCAEC (human coronary artery endothelial cells), and HLMVEC (human lung microvascular endothelial cells) cells were obtained from Cambrex and grown in EGM-2 supplemented with $10 \%$ fetal bovine serum (FBS). Cells were maintained in an incubator at $37^{\circ} \mathrm{C}$ in $5 \% \mathrm{CO}_{2}$ and $95 \%$ air. Cells from passage 4 or 5 were used in the experiments.

\section{Cell surface ELISA}

The expression of P-selectin on the cell surface was measured by the cell surface enzyme-linked immunosorbent assay (ELISA) as described by us previously
(28). Briefly, HPAE cells were seeded and cultured in 24-well plates until confluent. After stimulation with various concentrations of AII, cells were fixed immediately with $1 \%$ paraformaldehyde for $10 \mathrm{~min}$ at room temperature. After 3 washes with PBS and incubation with blocking buffer (3\% BSA in PBS) for $15 \mathrm{~min}$, the cells were incubated with mouse monoclonal antibody against P-selectin (1:200 dilution, $45 \mathrm{~min}$ at room temperature). Following washes with PBS, cells were incubated with HRP-conjugated goat anti-mouse antibody (1:4000 dilution, $45 \mathrm{~min}$ at room temperature). Peroxidase activity was detected using a 3,3',5,5'-tetramethylbenzidine substrate solution (TMB; Pierce, Rockford, IL, USA) and quantified by reading the plates on a spectrophotometric microplate reader at $450 \mathrm{~nm}$. All assays were done with triplicate samples and repeated three times.

\section{Monocyte adhesion assay}

Monocyte adhesion assay was performed as described by Patricia et al. (29). Briefly, HPAE cells were seeded $(50,000$ cells/well) and grown in gelatin-coated 24-well plates until confluent. Media were then replaced with RPMI 1640 containing 1\% FBS. After treatment, $1 \times 10^{5}$ THP-1 cells/well were added and allowed to adhere to endothelial cells with gentle rocking for $10 \mathrm{~min}$ at $37^{\circ} \mathrm{C}$. The endothelial monolayers were then gently washed with PBS to remove unbound monocytes and fixed with $1 \%$ paraformaldehyde $/ 1 \%$ glutaraldehyde-PBS solution. Bound monocytes were counted by phasecontrast microscopy. Eight microscopic fields were randomly selected for each experiment and quantified as bound monocytes/microscopic field.

\section{Immunoblotting}

Immunoblotting was performed as described by us previously (30). Briefly, cells were lysed in a lysis buffer containing $20 \mathrm{mM}$ Tris, $150 \mathrm{mM} \mathrm{NaCl}, 1 \mathrm{mM}$ EDTA, $1 \mathrm{mM}$ EGTA, $1 \%$ Triton $\mathrm{X}-100,2.5 \mathrm{mM}$ sodium pyrophosphate, $1 \mathrm{mM} \beta$-glycerolphosphate, $1 \mathrm{mM} \mathrm{Na}_{3} \mathrm{VO}_{4}$, $1 \mathrm{mM} \mathrm{NaF}(\mathrm{pH} 7.5)$, and $1 \%$ protease inhibitor mixture (Sigma). Protein concentrations were determined. Cell lysates were analyzed by SDS-PAGE and transferred onto polyvinylidene difluoride membranes. After transfer, membranes were blocked by incubating with $5 \%$ $(\mathrm{w} / \mathrm{v})$ nonfat dry milk in PBS solution with $0.05 \%$ Tween 20 for $1 \mathrm{~h}$ at room temperature or overnight at $4^{\circ} \mathrm{C}$. Membranes were then incubated with the indicated antibodies and developed using the enhanced chemiluminescence method (Pierce). Densitometry analysis was carried out using the Quantity One program (Biorad, Hercules, CA, USA). 
siRNA transfection of endothelial cells

Validated PKC $\alpha$ siRNA (Catalog number SI00301308) and PKD2 siRNA (Catalog number SI02224768) were obtained from Qiagen (Valencia, CA, USA). Fluorescein-conjugated negative control siRNA was obtained from Invitrogen. HPAE cells were cultured on $0.2 \%$ gelatin-coated plates. Twenty-four hours later, cells (50\% confluence) were transfected with $10 \mathrm{nM}$ siRNAs using Lipofectamine 2000 transfection reagent (Invitrogen) according to the manufacturer's protocol. Slight modification of the protocol was made in order to achieve high transfection efficiency. Namely, $1 \mu \mathrm{l}$ /well SilenceMag magnetic beads (Origene, Rockville, MD, USA) was added to the mixture containing the siRNAs and Lipofectamine in opti-MEM (Invitrogen). After adding the mixture to the cells, the plates were placed on a magnetic plate for $15 \mathrm{~min}$ and then returned to the $\mathrm{CO}_{2}$ incubator. Two days after the transfection procedure was accomplished, transfected cells were used for immunoblotting, surface ELISA, or monocyte adhesion assay.

\section{Statistics}

All values are expressed as means \pm S.E.M. Data were analyzed by one-way analysis of variance (ANOVA) followed by the Bonferroni test. A $P$ value $<0.05$ was considered significant.

\section{Results}

AII stimulates P-selectin surface expression in endothelial cells

P-selectin is known to localize in large secretory granules, Weibel-Palade bodies (WPBs), in endothelial cells (9). To determine whether AII can induce the rapid release of P-selectin from WPBs, we examined the effects of AII on P-selectin surface expression in HPAE cells. Cell surface ELISA showed that AII treatment increased surface expression of P-selectin in HPAE cells in a dose- and time-dependent manner (Fig. 1). The increase of P-selectin expression at the cell surface was observed as early as $5 \mathrm{~min}$ after AII stimulation and occurred even at low AII concentration $(1 \mathrm{nM})$. The maximum response was achieved at $100 \mathrm{nM}$ AII concentration. The peak level of P-selectin surface accumulation was achieved at $15 \mathrm{~min}$ after AII challenge. Surprisingly, AII at $1 \mu \mathrm{M}$ concentration had no effect on Pselectin surface expression. This could be due to induction of inhibitory signals on endothelial exocytosis at higher AII concentration or rapid activation of proteases that may remove P-selectin from the cell surface. Since $\mathrm{P}$-selectin is primarily stored in WPBs, our results suggest that AII can stimulate rapid WPB exocytosis in HPAE cells.

\section{AII induces transient PKD2 activation in endothelial cells}

PKD, which can be activated by AII signaling (12$14)$, has recently emerged as a key regulator of protein transport from the trans-Golgi network to the plasma membrane $(15-20)$. To explore the potential role of PKD in AII-triggered WPB exocytosis in endothelial cells, we first examined the expression and regulation of PKD in endothelial cells. The expression of PKD in endothelial cells was examined by using isoformspecific PKD antibodies (anti-PKD1, PKD2, and PKD3). The activity and isoform-specificity of the antibodies were confirmed using GST recombinant fusion proteins of PKD1, PKD2, and PKD3 (data not shown). Only PKD2 expression was detected in endothelial cells (Fig. 2A). Activation of PKD is dependent on the phosphorylation of two activation loop sites, Ser744 and Ser748, via a PKC-dependent signaling pathway. Using the antibody against the phosphorylated ser744 and 748 of PKD2, we showed that AII induced PKD2 phosphorylation in HPAE cells in a time and dose-dependent fashion (Fig. 2: B and C).
A

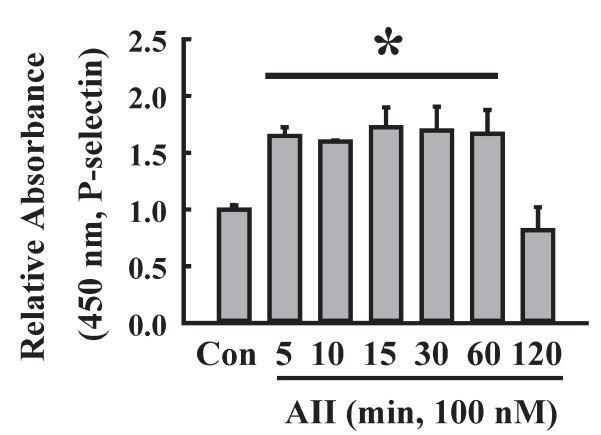

B

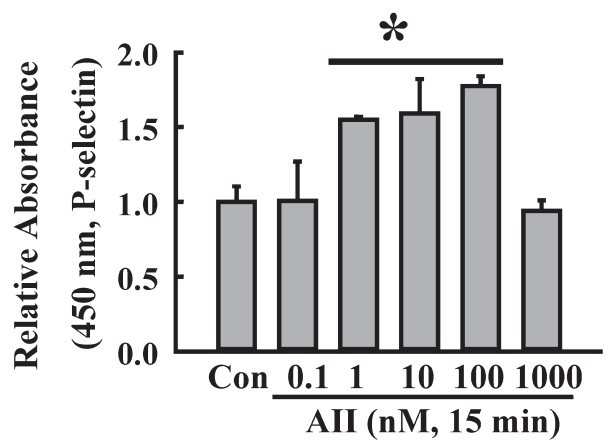

Fig. 1. AII stimulates P-selectin surface expression in HPAE cells. HPAE cells were treated with AII as indicated. Surface expreesion of P-selectin was quantified by a cell surface ELISA following AII treatment as described in Materials and Methods. Data are presented as means \pm S.E.M. An asterisk indicates a value significantly different from that of control cells (Con) without AII treatment, $P<0.05$. 
A

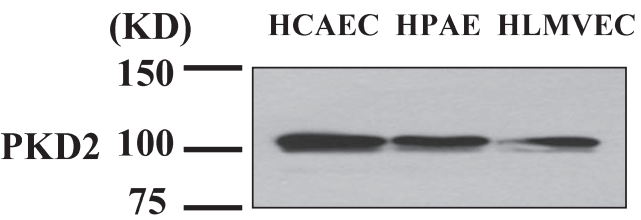

B

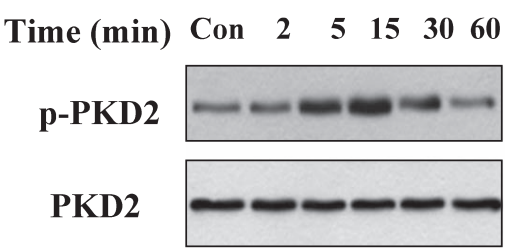

C

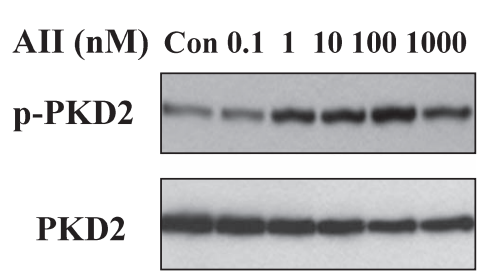

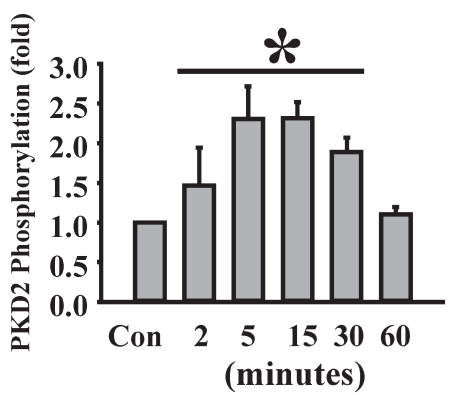

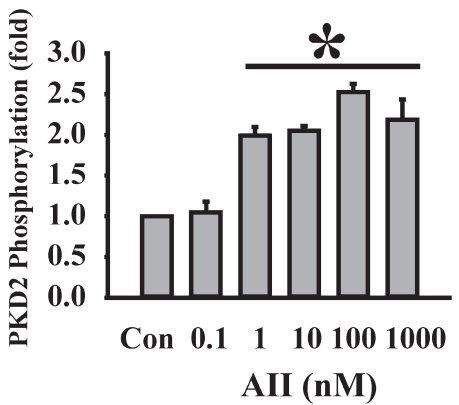

Fig. 2. PKD Expression and AII-induced PKD2 phosphorylation in endothelial cells. A: cell lysates $(20 \mu \mathrm{g}$ protein/lane) from HPAE (human pulmonary artery endothelial cells), HCAEC (human coronary artery endothelial cells), and HLMVEC (human lung microvascular endothelial cells) were resolved by SDS-PAGE, transferred onto polyvinylidene difluoride membranes, and immunoblotted with anti-PKD2 antibody. Time course $(100 \mathrm{nM})(\mathrm{B})$ and dose-response $(15 \mathrm{~min})(\mathrm{C})$ of AII-induced PKD2 phosphorylation in HPAE cells were assessed. HPAE cells were pre-treated with AII as indicated. Cell lysates were resolved by SDS-PAGE, transferred onto polyvinylidene difluoride membranes, and immunoblotted with anti-PKD (pSer744/748) antibody. The same membrane was stripped and blotted with anti-PKD2 antibody. Representative blots and bar graphs show the change of PKD2 phosphorylation. Results shown are representative of three independent experiments. Data are presented as means \pm S.E.M. An asterisk indicates a value significantly different from that of control cells (Con) without AII challenge, $P<0.05$.
Role of PKD2 in AII-induced P-selectin surface expression in endothelial cells

To confirm the functional role of PKD2 in AIIregulated P-selectin surface expression, we used a siRNA against PKD2 to knock down its expression in HPAE cells. The effect of the siRNA on P-selectin surface expression was examined. PKD2 siRNA transfection specifically reduced the expression of PKD2 in HPAE cells (Fig. 3A). Knock-down of PKD2 expression caused a significant reduction of AII-induced P-selectin surface expression when compared with that of cells transfected with the control siRNA (Fig. 3B). Our results indicate that PKD2 is an important regulator of $\mathrm{P}$-selectin surface expression in endothelial cells.

\section{AT1 receptor mediates AII-induced PKD2 activation and endothelial exocytosis}

To identify the subtype of angiotensin II receptors that mediates AII responses in endothelial cells, we pretreated HPAE cells with selective AT1- or AT2-receptor antagonists, and their effects on PKD2 activation and P-selectin surface expression were then examined. AIIinduced PKD2 activation and P-selectin surface expression were markedly decreased by pre-treatment with the AT1-receptor antagonist telmisartan, but not the AT2- receptor antagonist PD123,319 (Fig. 4). Thus, AT1receptor signaling is necessary for AII-induced PKD2 activation and P-selectin surface expression. Our findings provide a new mechanism for AT1 receptormediated endothelial inflammatory responses.

PKC $\alpha$-dependent PKD2 phosphorylation and P-selectin surface expression following AII challenge

PKC has been reported to mediate various cellular responses of AII $(31-36)$. We have shown that PKCa activation by thrombin mediates $\mathrm{P}$-selectin surface expression in endothelial cells (28). PKC $\alpha$ is highly expressed in endothelial cells (37). Here, we examined whether AII-induced PKD activation and P-selectin surface expression require $\mathrm{PKC} \alpha$ activation in HPAE cells. Transfection of a PKC $\alpha$-specific siRNA decreased PKC $\alpha$ expression in HPAE cells (Fig. 5A), whereas PKD2 expression was not affected by the transfection. PKD2 activation upon AII stimulation in HPAE cells was inhibited by the siRNA transfection (Fig. 5B), which correlated with decreased P-selectin surface expression (Fig. 5C). Thus, AII-induced PKD2 activation and $\mathrm{P}$-selectin surface expression in HPAE cells are mediated by the PKC $\alpha$ signaling pathway. 
A

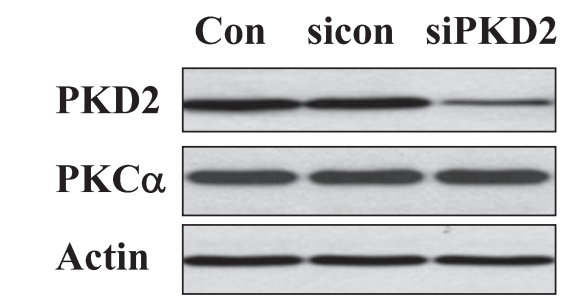

B

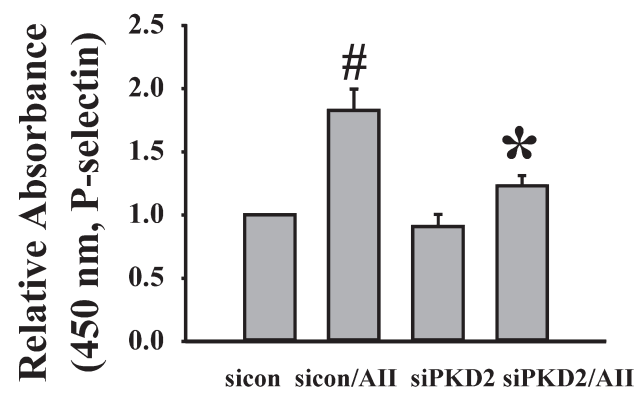

Fig. 3. Knockdown of PKD2 expression inhibits AII-induced Pselectin surface expression. HPAE cells were transfected with $10 \mathrm{nM}$ scrambled control (sicon), PKD2-specific siRNAs (siPKD2), or mock-transfected (Con). A: Cell lysates collected 2 days after the transfection were resolved by SDS-PAGE and immunoblotted with anti-PKD2, anti-PKC $\alpha$, or anti-actin antibodies. The blots are representative of three separate experiments. B: HPAE cells were treated with AII $(100 \mathrm{nM}, 15 \mathrm{~min})$. P-selectin surface expression was assessed 2 days after the transfection. Data are presented as means \pm S.E.M. * indicates a value significantly different from that of cells transfected with the control siRNA (sicon) and challenged with AII, $P<0.05$; ${ }^{\#}$ indicates a value significantly different from that of cells transfected with the control siRNA (sicon), $P<0.05$.

\section{AII induces P-selectin-dependent monocyte adhesion to endothelial cells}

To evaluate the role of P-selectin surface expression in AII-induced endothelial adhesiveness, we examined whether AII-induced P-selectin expression promotes monocyte adhesion to endothelial cells. HPAE cells were treated with AII $(100 \mathrm{nM}, 15 \mathrm{~min})$. Adhesion assays were then performed. Very few of THP-1 monocytes were observed to adhere to un-stimulated HPAE cells. The number of THP-1 monocytes bound to AIIstimulated HPAE cells was significantly higher than that bound to the control endothelial monolayer. Pretreatment of HPAE cells for $30 \mathrm{~min}$ with P-selectinblocking monoclonal antibody (1:200) markedly reduced AII-induced monocyte adhesion (Fig. 6). This study demonstrated a functional correlation of rapid P-selectin surface expression and monocyte adhesion induced by AII.
A
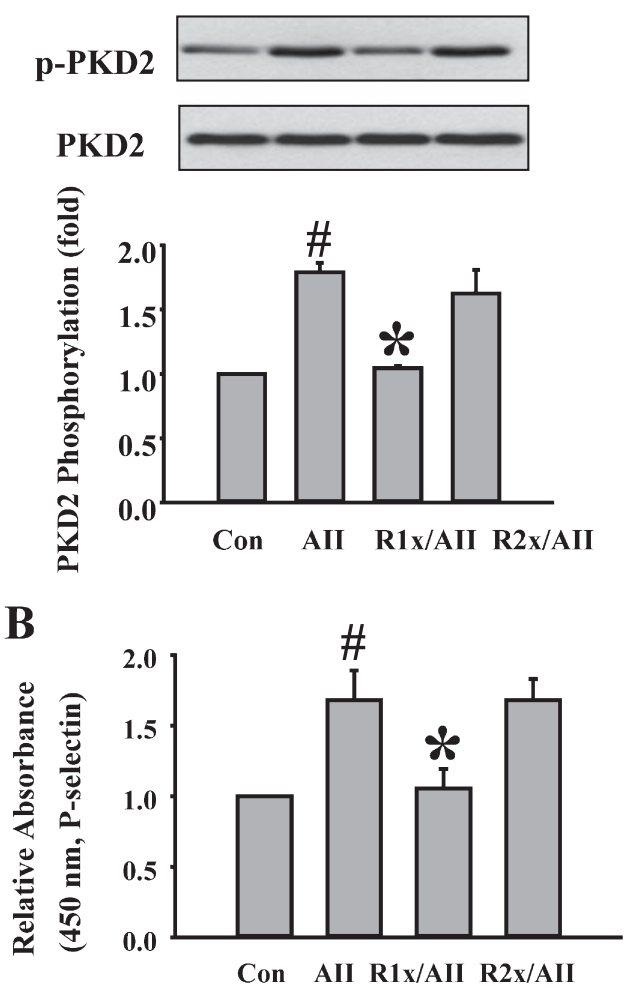

Fig. 4. Blockade of AT1 receptor inhibited AII-induced PKD2 activation and P-selectin surface expression. HPAE cells were not pre-treated or pre-treated with either the AT1-receptor antagonist (R1x, $1 \mu \mathrm{M}$ telmisartan) or AT2-receptor antagonist (R2x, $1 \mu \mathrm{M}$ PD $123,319)$ for $30 \mathrm{~min}$ prior to AII $(100 \mathrm{nM}, 15 \mathrm{~min})$ treatment. HPAE cells without any treatment were used as the control (Con). A: cell lysates were resolved by SDS-PAGE, transferred onto polyvinylidene difluoride membranes, and immunoblotted with anti-PKD (pSer744 1748) antibody. The same membrane was stripped and blotted with anti-PKD2 antibody. Representative blots and bar graphs show the change of PKD2 phosphorylation. Results shown are representative of three independent experiments. B: cell surface P-selectin expression in HPAE cells was assessed as described in Materials and Methods. Data are presented as means \pm S.E.M. * indicates a value significantly different from that of cells treated with AII alone (AII), $P<0.05$; " indicates a value significantly different from that of cells without any treatment (Con), $P<0.05$.

\section{PKCa and PKD2 siRNAs inhibit AII-induced monocyte} adhesion to endothelial cells

To confirm the functional role of PKC $\alpha$ and PKD2 in AII-induced monocyte/endothelial cell adhesion, we used the siRNAs against PKC $\alpha$ and PKD2 to knock down their expression in HPAE cells. The effects of the siRNAs on THP-1 monocyte adhesion to HPAEs were examined. Knock-down of PKC $\alpha$ or PKD2 expression caused a significant reduction of AII-induced monocyte adhesion to HPAEs (Fig. 7). Our results indicate that PKC $\alpha$ and PKD2 play important roles in AII-induced monocyte adhesion to endothelial cells. 
A

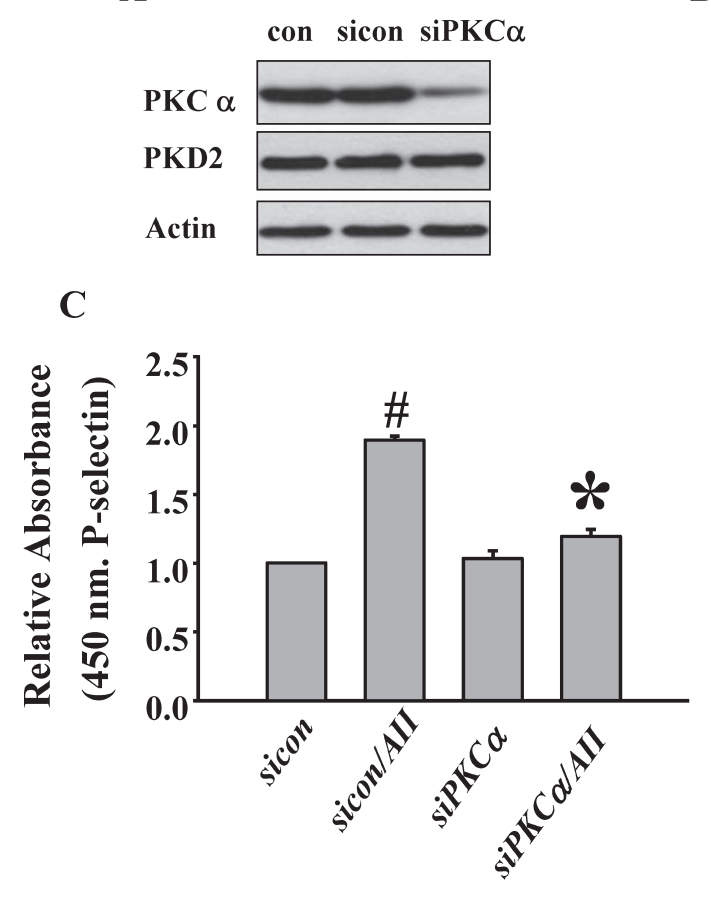

B

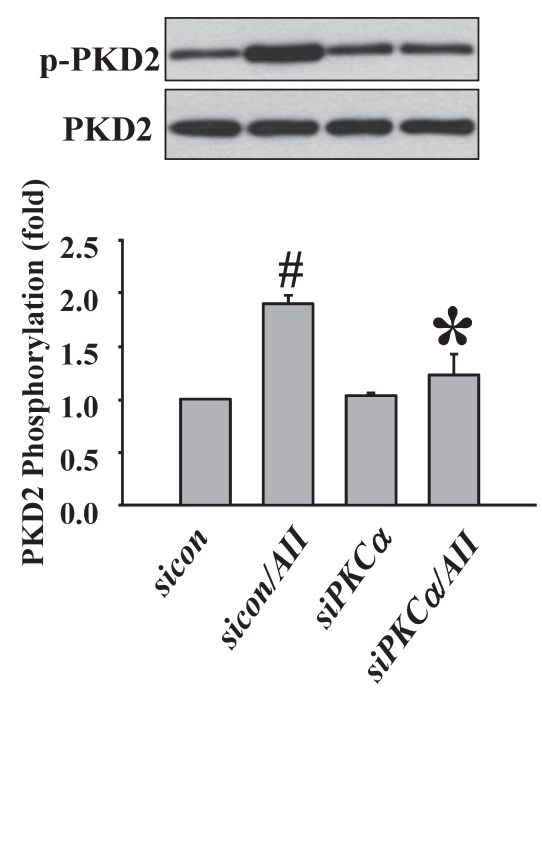

Fig. 5. Requirement for $\mathrm{PKC} \alpha$ in signaling AII-induced PKD2 phosphorylation and P-selectin surface expression. HPAE cells were transfected with $10 \mathrm{nM}$ scrambled control (sicon), PKC $\alpha$-specific siRNAs ( $\operatorname{siPKC} \alpha$ ), or mock-transfected (con). The cells were challenged with AII $(100 \mathrm{nM}, 15 \mathrm{~min}) 2$ days later. A: Cell lysates were resolved by SDSPAGE, transferred on PVDF membranes, and immunoblotted with anti-PKC $\alpha$, anti-PKD2, or anti-actin antibody. B: Representative blots and bar graphs show the change of PKD2 phosphorylation. Results shown are representative of three independent experiments. C: Cell surface Pselectin expression in HPAE cells was assessed as described in Materials and Methods. Data are presented as means \pm S.E.M. * indicates a value significantly different from that of control cells (sicon) treated with AII, $P<0.05$; ${ }^{*}$ indicates a value significantly different from that of cells transfected with the control siRNA (sicon), $P<0.05$.
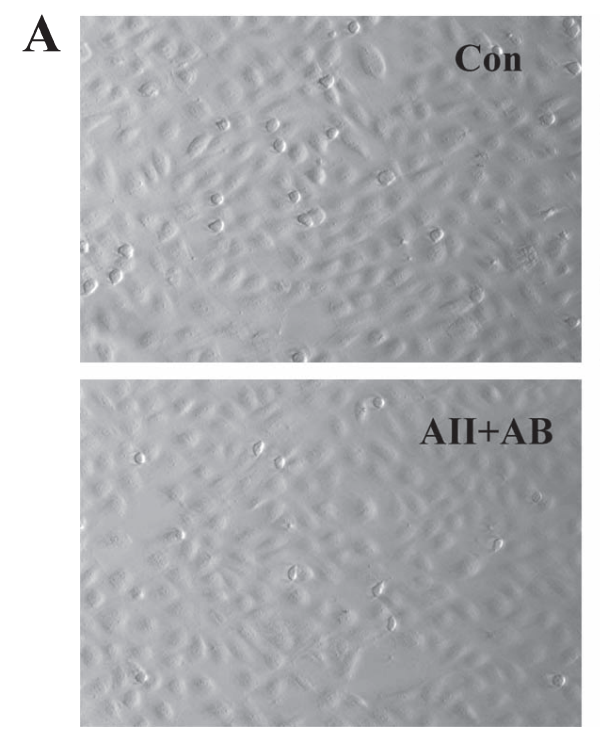
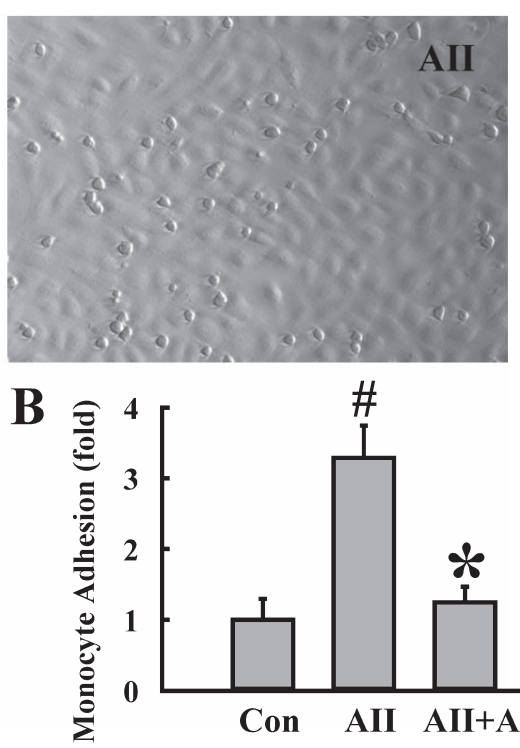

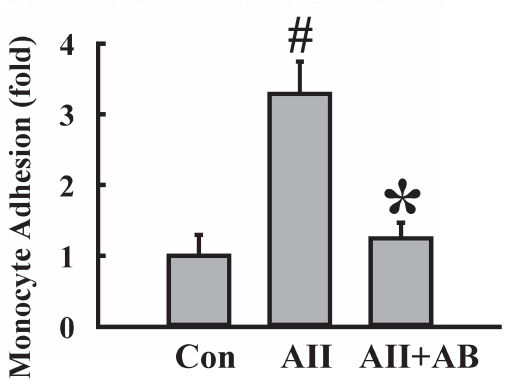

Fig. 6. Inhibition of AII-induced monocyte adhesion to endothelial cells by a Pselectin function-blocking antibody. HPAE cells were stimulated with AII $(100 \mathrm{nM}$, $15 \mathrm{~min})$ or pretreated with P-selectinblocking antibody $(1: 200)$ for $30 \mathrm{~min}$ before AII challenge. A: Representative images of THP-1 monocytes bound to an endothelial monolayer without AII treatment (Con), endothelial monolayer treated with AII alone (AII), and endothelial monolayer pretreated with $\mathrm{P}$-selectin-blocking antibody and then treated with AII (AII + AB). B: THP-1 monocytes bound to HPAE cells were assessed as described in Materials and Methods. Data are presented as means \pm S.E.M. * indicates a value significantly different from that of cells treated with AII alone, $P<0.05$; \# indicates a value significantly different from that of cells without any treatment (Con), $P<0.05$.

\section{Discussion}

It is now well accepted that AII possesses pro-inflammatory activity and is involved in various inflammatory processes that may be crucial for the progression of cardiovascular diseases $(2-4,38)$. The leukocyteendothelium interaction induced by AII may contribute to the initiation of vascular inflammation $(7,8)$. Pselectin, when expressed at the plasma membrane of endothelial cells, can mediate the initial capture of leukocytes $(5,6)$. Several studies have indicated that AII may trigger P-selectin surface expression to initiate leukocyte adhesion to endothelial cells $(8,39,40)$. Our results suggest that AII-induced PKD2 activation promotes the surface exposure of P-selectin and monocyte adhesion to endothelial cells.

AII has also been shown to induce platelet-endothelial cell interactions in cerebral venules that included rolling and adhesion of platelets on the endothelial cells (41). Importantly, AII-induced platelet/endothelial cell inter- 


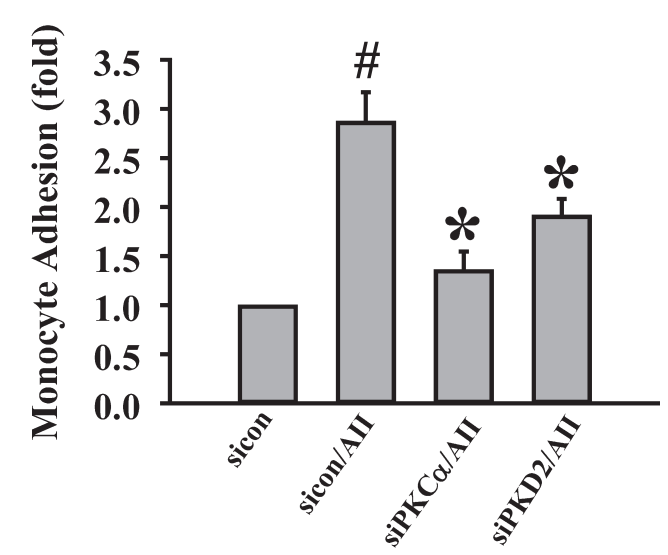

Fig. 7. Knockdown of $\mathrm{PKC} \alpha$ or PKD2 expression inhibits AIIinduced monocyte adhesion to endothelial cells. HPAE cells were transfected with $10 \mathrm{nM}$ scrambled control (sicon), PKC $\alpha$-specific siRNA ( $\operatorname{siPKC} \alpha$ ), or PKD2-specific siRNAs (siPKD2). Two days later, the HPAE cells were treated with AII (100 nM, 15 min). THP-1 monocyte adhesion was assessed as described in Materials and Methods. Data are presented as means \pm S.E.M. * indicates a value significantly different from that of cells transfected with the control siRNA (sicon) and challenged with AII, $P<0.05$; ${ }^{\#}$ indicates a value significantly different from that of cells transfected with the control siRNA (sicon), $P<0.05$.

actions were attenuated by treatment with P-selectin antibody, suggesting a critical role of P-selectin in their interactions. Thus, our finding that AII can directly trigger P-selectin surface expression via PKD2 activation may provide a potential mechanism of AIIinduced platelet/endothelial cell interactions.

AII signaling is mediated by AT1 and AT2 receptors, which may have antagonistic effects against each other (42). AT1-receptor activation and the resultant induction of local vascular inflammation have been suggested to play a central role in atherosclerosis (43). Several signaling pathways have been reported to mediate the pro-inflammatory effects of AT1 receptors (38), including the activation of NADPH oxidase, protein kinases, and phospholipases, which can mediate the up-regulation of NF- $\kappa \mathrm{B}$. NF- $\kappa \mathrm{B}$ activation then leads to increased expression of cytokines, chemokines, and adhesion molecules. Our present study suggests that PKD2 activation is a new pro-inflammatory signaling mechanism of the AT1 receptor. The transient and rapid PKD2 activation by AT1-receptor signaling appears to induce the early endothelial adhesiveness by stimulating endothelial exocytosis, which may play an important role in the initiation of vascular inflammation. Even though the acute effect of AII on P-selectin surface expression is independent of de novo protein synthesis, we cannot exclude the possibility that PKD2 may also regulate the transcription of pro-inflammatory molecules such as ICAM-1 and VCAM-1. Indeed, PKD has been reported to mediate NF- $\kappa \mathrm{B}$ activation $(44,45)$. A recent study demonstrated that PKD2-mediated NF- $\kappa \mathrm{B}$ activation is required for LPA-induced IL-8 production in epithelial cells (44). Thus, PKD2 may not only mediate the acute effects of AII on the early onset of endothelial adhesiveness by regulating membrane trafficking, it may also modulate the persistent and chronic inflammatory responses of AII by stimulating the transcription of proinflammatory mediators. Overall, our study indicates that PKD2 activation is a pro-inflammatory signal induced by the AT1 receptor in endothelial cells.

PKC activation is a key signaling mechanism in AII-induced cellular functions $(31-36)$. Stimulation of AII type 1 receptor can activate phospholipase C (PLC) followed by production of 1,2-diacylglycerol (DAG) and inositol 1,4,5-trisphosphate $\left(\mathrm{IP}_{3}\right)$ (46). Binding of DAG to PKC leads to activation and translocation of PKC to the plasma membrane. The role of PKC in regulated membrane trafficking is well established (47). We have shown that PKC can regulate the exocytotic machinery in endothelial cells (28). In our present study, we demonstrated that AII-induced P-selectin surface expression required PKC $\alpha$ activation. Since the localization and activation of PKD are regulated by its binding to DAG and PKC (21), PKD may serve to integrate the signals from PKC and DAG. Several recent studies indicate that PKD is highly mobile and can shuttle between different subcellular compartments, and the subcellular localization of PKD can be regulated by extracellular stimuli $(48-50)$. Thus, locally produced DAG by AII may recruit PKC and PKD to the plasma membrane, thereby triggering endothelial exocytosis and the resultant P-selectin surface expression.

Further studies are needed to determine the downstream targets of PKD2 that mediate AII-induced Pselectin surface expression. Recently (18), the Cterminus of PKD (both PKD1 and PKD2) was identified to contain a postsynaptic density-95/discs large/zonula occludens-1 (PDZ)-binding motif, which are short peptide sequences that can bind to PDZ proteins containing 70-90 amino acid PDZ domains. PDZ proteins are known to control the transport and function of membrane proteins $(51,52)$. It has been suggested that PKD may regulate the translocation of proteins to the plasma membrane by its interaction with PDZ proteins (18). It will be interesting to know whether PDZ proteins are involved in AII stimulated P-selectin surface expression.

In summary, our study suggests that AII can directly trigger endothelial exocytosis via $\mathrm{PKC} \alpha$-dependent PKD2 activation. The resultant P-selectin surface expression could be an important mechanism in endothelial inflammation triggered by AII signaling. 


\section{References}

1 Skeggs LT, Dorer FE, Levine M, Lentz KE, Kahn JR. The biochemistry of the renin-angiotensin system. Adv Exp Med Biol. 1980;130:1-27.

2 Sironi L, Gelosa P, Guerrini U, Banfi C, Crippa V, Brioschi M, et al. Anti-inflammatory effects of AT1 receptor blockade provide end-organ protection in stroke-prone rats independently from blood pressure fall. J Pharmacol Exp Ther. 2004;311:989995.

3 Takata Y, Chu V, Collins AR, Lyon CJ, Wang W, Blaschke F, et al. Transcriptional repression of ATP-binding cassette transporter A1 gene in macrophages: a novel atherosclerotic effect of angiotensin II. Circ Res. 2005;97:e88-e96.

4 Toko H, Zou Y, Minamino T, Masaya M, Harada M, Nagai T, et al. Angiotensin II type 1a receptor is involved in cell infiltration, cytokine production, and neovascularization in infarcted myocardium. Arterioscler Thromb Vasc Biol. 2004;24:664-670.

5 Springer TA. Traffic signals for lymphocyte recirculation and leukocyte emigration: the multistep paradigm. Cell. 1994;76: 301-314.

6 Mayadas TN, Johnson RC, Rayburn H, Hynes RO, Wagner DD. Leukocyte rolling and extravasation are severely compromised in P selectin-deficient mice. Cell. 1993;74:541-554.

7 Alvarez A, Cerda-Nicolas M, Naim Abu Nabah Y, Mata M, Issekutz AC, Panes J, et al. Direct evidence of leukocyte adhesion in arterioles by angiotensin II. Blood. 2004;104:402408.

8 Piqueras L, Kubes P, Alvarez A, O’Connor E, Issekutz AC, Esplugues JV, et al. Angiotensin II induces leukocyte-endothelial cell interactions in vivo via $\mathrm{AT}(1)$ and $\mathrm{AT}(2)$ receptormediated P-selectin upregulation. Circulation. 2000;102:2118 2123.

9 Rondaij MG, Bierings R, Kragt A, van Mourik JA, Voorberg J. Dynamics and plasticity of Weibel-Palade bodies in endothelial cells. Arterioscler Thromb Vasc Biol. 2006;26:1002-1007.

10 Hamilton KK, Sims PJ. Changes in cytosolic $\mathrm{Ca}^{2+}$ associated with von Willebrand factor release in human endothelial cells exposed to histamine. Study of microcarrier cell monolayers using the fluorescent probe indo-1. J Clin Invest. 1987;79:600 608.

11 Pinsky DJ, Naka Y, Liao H, Oz MC, Wagner DD, Mayadas TN, et al. Hypoxia-induced exocytosis of endothelial cell WeibelPalade bodies. A mechanism for rapid neutrophil recruitment after cardiac preservation. J Clin Invest. 1996;97:493-500.

12 Chiu T, Rozengurt E. PKD in intestinal epithelial cells: rapid activation by phorbol esters, LPA, and angiotensin through PKC. Am J Physiol Cell Physiol. 2001;280:C929-C942.

13 Romero DG, Welsh BL, Gomez-Sanchez EP, Yanes LL, Rilli S, Gomez-Sanchez CE. Angiotensin II-mediated protein kinase D activation stimulates aldosterone and cortisol secretion in H295R human adrenocortical cells. Endocrinology. 2006;147: 6046-6055.

14 Tan M, Xu X, Ohba M, Cui MZ. Angiotensin II-induced protein kinase $\mathrm{D}$ activation is regulated by protein kinase Cdelta and mediated via the angiotensin II type 1 receptor in vascular smooth muscle cells. Arterioscler Thromb Vasc Biol. 2004;24: 2271-2276.

15 Hausser A, Storz P, Martens S, Link G, Toker A, Pfizenmaier K. Protein kinase $\mathrm{D}$ regulates vesicular transport by phosphorylat- ing and activating phosphatidylinositol-4 kinase IIIbeta at the Golgi complex. Nat Cell Biol. 2005;7:880-886.

16 Li J, O'Connor KL, Hellmich MR, Greeley GH Jr, Townsend $\mathrm{CM} \mathrm{Jr}$, Evers BM. The role of protein kinase D in neurotensin secretion mediated by protein kinase C-alpha/-delta and Rho/Rho kinase. J Biol Chem. 2004;279:28466-28474.

17 Matthews SA, Iglesias T, Rozengurt E, Cantrell D. Spatial and temporal regulation of protein kinase D (PKD). Embo J. 2000;19:2935-2945.

18 Sanchez-Ruiloba L, Cabrera-Poch N, Rodriguez-Martinez M, Lopez-Menendez C, Jean-Mairet RM, Higuero AM, et al. Protein kinase D intracellular localization and activity control kinase D-interacting substrate of $220-\mathrm{kDa}$ traffic through a postsynaptic density-95/discs large/zonula occludens-1-binding motif. J Biol Chem. 2006;281:18888-18900.

19 Van Lint J, Rykx A, Maeda Y, Vantus T, Sturany S, Malhotra V, et al. Protein kinase D: an intracellular traffic regulator on the move. Trends Cell Biol. 2002;12:193-200.

20 Yeaman C, Ayala MI, Wright JR, Bard F, Bossard C, Ang A, et al. Protein kinase D regulates basolateral membrane protein exit from trans-Golgi network. Nat Cell Biol. 2004;6:106-112.

21 Wang QJ. PKD at the crossroads of DAG and PKC signaling. Trends Pharmacol Sci. 2006;27:317-323.

22 Kennett SB, Roberts JD, Olden K. Requirement of protein kinase $\mathrm{C}$ micro activation and calpain-mediated proteolysis for arachidonic acid-stimulated adhesion of MDA-MB-435 human mammary carcinoma cells to collagen type IV. J Biol Chem. 2004;279:3300-3307.

23 Rozengurt E, Rey O, Waldron RT. Protein kinase D signaling. J Biol Chem. 2005;280:13205-13208.

24 Wong C, Jin ZG. Protein kinase C-dependent protein kinase D activation modulates ERK signal pathway and endothelial cell proliferation by vascular endothelial growth factor. J Biol Chem. 2005;280:33262-33269.

25 Rey O, Reeve JR Jr, Zhukova E, Sinnett-Smith J, Rozengurt E. $G$ protein-coupled receptor-mediated phosphorylation of the activation loop of protein kinase $\mathrm{D}$ : dependence on plasma membrane translocation and protein kinase Cepsilon. J Biol Chem. 2004;279:34361-34372.

26 Sturany S, Van Lint J, Gilchrist A, Vandenheede JR, Adler G, Seufferlein T. Mechanism of activation of protein kinase $\mathrm{D} 2(\mathrm{PKD} 2)$ by the $\mathrm{CCK}(\mathrm{B}) /$ gastrin receptor. J Biol Chem. 2002;277:29431-29436.

27 Yuan J, Slice LW, Gu J, Rozengurt E. Cooperation of Gq, Gi, and $\mathrm{G} 12 / 13$ in protein kinase $\mathrm{D}$ activation and phosphorylation induced by lysophosphatidic acid. J Biol Chem. 2003;278:48824891.

28 Fu J, Naren AP, Gao X, Ahmmed GU, Malik AB. Proteaseactivated receptor-1 activation of endothelial cells induces protein kinase Calpha-dependent phosphorylation of syntaxin 4 and Munc18c: role in signaling p-selectin expression. J Biol Chem. 2005;280:3178-3184.

29 Patricia MK, Kim JA, Harper CM, Shih PT, Berliner JA, Natarajan R, et al. Lipoxygenase products increase monocyte adhesion to human aortic endothelial cells. Arterioscler Thromb Vasc Biol. 1999; 19:2615-2622.

30 Low B, Liang M, Fu J. p38 Mitogen-activated protein kinase mediates sidestream cigarette smoke-induced endothelial permeability. J Pharmacol Sci. 2007;104:225-231.

31 Oriji GK. Angiotensin II-induced ET and PGI2 release in rat 
aortic endothelial cells is mediated by PKC. Prostaglandins Leukot Essent Fatty Acids. 1999;61:113-117.

32 Otani A, Takagi H, Oh H, Koyama S, Honda Y. Angiotensin II induces expression of the Tie2 receptor ligand, angiopoietin-2, in bovine retinal endothelial cells. Diabetes. 2001;50:867-875.

33 Saito S, Hirata Y, Emori T, Imai T, Marumo F. Angiotensin II activates endothelial constitutive nitric oxide synthase via AT1 receptors. Hypertens Res. 1996;19:201-206.

34 Stanimirovic D, Morley P, Ball R, Hamel E, Mealing G, Durkin JP. Angiotensin II-induced fluid phase endocytosis in human cerebromicrovascular endothelial cells is regulated by the inositol-phosphate signaling pathway. J Cell Physiol. 1996;169: 455-467.

35 Uchiyama-Tanaka Y, Matsubara H, Nozawa Y, Murasawa S, Mori Y, Kosaki A, et al. Angiotensin II signaling and HB-EGF shedding via metalloproteinase in glomerular mesangial cells. Kidney Int. 2001;60:2153-2163.

36 Yoshiji H, Kuriyama S, Noguchi R, Ikenaka Y, Kitade M, Kaji $\mathrm{K}$, et al. Angiotensin-II and vascular endothelial growth factor interaction plays an important role in rat liver fibrosis development. Hepatol Res. 2006;36:124-129.

37 Holinstat M, Mehta D, Kozasa T, Minshall RD, Malik AB. Protein kinase Calpha-induced p115RhoGEF phosphorylation signals endothelial cytoskeletal rearrangement. J Biol Chem. 2003;278:28793-28798.

38 Ruiz-Ortega M, Esteban V, Ruperez M, Sanchez-Lopez E, Rodriguez-Vita J, Carvajal G, et al. Renal and vascular hypertension-induced inflammation: role of angiotensin II. Curr Opin Nephrol Hypertens. 2006; 15:159-166.

39 Soehnlein O, Schmeisser A, Cicha I, Reiss C, Ulbrich H, Lindbom L, et al. ACE inhibition lowers angiotensin-II-induced monocyte adhesion to HUVEC by reduction of $\mathrm{p} 65$ translocation and AT 1 expression. J Vasc Res. 2005;42:399-407.

40 Tayeh MA, Scicli AG. Angiotensin II and bradykinin regulate the expression of P-selectin on the surface of endothelial cells in culture. Proc Assoc Am Physicians. 1998;110:412-421.

41 Ishikawa M, Sekizuka E, Yamaguchi N, Nakadate H, Terao S, Granger DN, et al. Angiotensin II type 1 receptor signaling contributes to platelet-leukocyte-endothelial cell interactions in the cerebral microvasculature. Am J Physiol Heart Circ Physiol. 2007;292:H2306-H2315.
42 Watanabe T, Barker TA, Berk BC. Angiotensin II and the endothelium: diverse signals and effects. Hypertension. 2005;45: 163-169.

43 Nickenig G. Central role of the AT(1)-receptor in atherosclerosis. J Hum Hypertens. 2002;16 Suppl 3:S26-S33.

44 Chiu T, Leung WY, Moyer MP, Strieter RM, Rozengurt E. Protein kinase D2 mediates lysophosphatidic acid-induced interleukin-8 production in nontransformed, human colonic epithelial cells through NF-\{kappa\}B. Am J Physiol Cell Physiol. 2006;292:C767-C777.

45 Storz P, Doppler H, Toker A. Activation loop phosphorylation controls protein kinase D-dependent activation of nuclear factor kappaB. Mol Pharmacol. 2004;66:870-879.

46 Sadoshima J, Izumo S. Signal transduction pathways of angiotensin II-induced c-fos gene expression in cardiac myocytes in vitro. Roles of phospholipid-derived second messengers. Circ Res. 1993;73:424-438.

47 Alvi F, Idkowiak-Baldys J, Baldys A, Raymond JR, Hannun YA. Regulation of membrane trafficking and endocytosis by protein kinase $\mathrm{C}$ : emerging role of the pericentrion, a novel protein kinase C-dependent subset of recycling endosomes. Cell Mol Life Sci. 2006;64:263-270.

48 Auer A, von Blume J, Sturany S, von Wichert G, Van Lint J, Vandenheede $J$, et al. Role of the regulatory domain of protein kinase D2 in phorbol ester binding, catalytic activity, and nucleocytoplasmic shuttling. Mol Biol Cell. 2005;16:43754385.

49 Chen J, Lu G, Wang QJ. Protein kinase C-independent effects of protein kinase D3 in glucose transport in L6 myotubes. Mol Pharmacol. 2005;67:152-162.

50 Waldron RT, Rey O, Zhukova E, Rozengurt E. Oxidative stress induces protein kinase $\mathrm{C}$-mediated activation loop phosphorylation and nuclear redistribution of protein kinase D. J Biol Chem. 2004;279:27482-27493.

51 Biber J, Gisler SM, Hernando N, Murer H. Protein/protein interactions (PDZ) in proximal tubules. J Membr Biol. 2005; 203:111-118

52 Lin Y, Jover-Mengual T, Wong J, Bennett MV, Zukin RS. PSD95 and PKC converge in regulating NMDA receptor trafficking and gating. Proc Natl Acad Sci U S A. 2006;103:19902-19907. 